Escuela de Ciencias Sociales y Humanidades, UNED, Costa Rica

https://revistas.uned.ac.cr/index.php/espiga

ISSN: 1409-4002・e-ISSN: 2215-454X

\title{
Trumpismo: Un americanismo desfigurado ${ }^{1}$
}

\author{
Mimi Yang * \\ http://orcid.org/0000-0003-4070-5323
}

Traducción: L. Cecilia Ojeda

Recibido: 7 de enero de 2021 • Aceptado: 4 de febrero de 2021

\section{Resumen}

La actual turbulencia cultural en los Estados Unidos de América deriva del fenómeno político del Trumpismo, enraizado en un concepto desarrollado por John Higham llamado nativismo. Un americanismo ${ }^{2}$ de doble eje se ha desfigurado en una mutua y destructiva interacción. El americanismo vertical establece un orden jerarquizado que asegura el poder de una clase blanca dominante en una sociedad homogénea racial y culturalmente. El americanismo horizontal, basado en los ideales de Martin Luther King Jr. y Barack Obama, busca lograr la igualdad entre razas ${ }^{3}$, creencias y clases sociales diversas. La línea del color (en términos de Dubois) deviene en un límite cuya actual tensión máxima separa estos dos ejes, desfigurando culturalmente a la nación.

Palabras clave: Trumpismo, nativismo, inmigración.

* Doctora en Lengua y Literatura Española por la Universidad de Arizona. Catedrática Emérita de Lenguas Modernas en Carthage College, Wisconsin, EUA. Autora del libro The Tricultural Personality (Chinese, Hispanic, English): A Paradigm for Connecting Culture Differences (Edwin Mellen, 2014). Autora de

\footnotetext{
${ }^{1}$ Este artículo fue publicado originalmente en inglés por Palgrave Communications. Su versión en inglés, «Trumpism: a disfigured Americanism», puede consultarse en la siguiente dirección: https://www.nature.com/articles/s41599-018-0170-0. Se traduce bajo acuerdo con la autora, cuya publicación fue aprobada por el comité editorial de la Revista Espiga.

${ }^{2}$ Nota de la traductora. En esta traducción se usa el término americanismo como equivalente del inglés «Americanism» usado en el artículo original. Su uso se refiere a los Estados Unidos de América específicamente, no al continente americano en general.

${ }^{3}$ Nota del editor. La palabra raza es un término cuyo uso en el castellano se ha venido cambiando a su sentido biológico de clasificación de especies, por esto se evita utilizarla para separar grupos humanos, lo más adecuado en estos casos es hablar de etnias o poblaciones. No obstante, en el contexto estadounidense, país de origen de la autora del artículo, el concepto de race (raza) tiene una connotación más compleja, relacionada en este caso específico con el discurso antirracista, por lo cual, en relación con la situación sociopolítica que vive el país norteamericano, la Revista Espiga ha decidido mantener esta palabra en la traducción del texto que se presenta en esta edición.
} 
numerosos artículos sobre múltiples aspectos de la literatura y cultura de Latinoamérica, como de temas estadounidenses. En 2004 se le otorgó el premio Wisconsin Global Educator Award at Higher Education Level. Correo: myang@carthage.edu

\title{
Trumpism: a disfigured Americanism
}

\begin{abstract}
The current cultural turmoil in the U.S. is much associated with Trumpism. This article asserts that Trumpism has its ideological root in nativism, a cultural tradition perpetuated by John Higham. To point out the disfigured Americanism in Trumpism, this paper theorizes the vertical America and the horizontal America, and dissects their complex interplay and symbiosis in an evolving American culture. The vertical Americanism sets hierarchies to secure power and control as well as maintain racial and cultural «purity»; the horizontal Americanism, epitomized by Martin Luther King and Barack Obama, equalizes and connects across races, creeds, and social classes. The color line (in Dubois' term) thus becomes a converging and diverging boundary between the two Americas; it harbors and delineates Trumpism. It is argued that disfigurement of Americanism comes from a disruptive and destructive interplay of the vertical and the horizontal in Trump's America.
\end{abstract}

Key words: Trumpism, nativism, immigration.

\section{Trumpisme: un américainisme déformé}

\section{Résumé}

L'actuelle turbulence culturelle dans les États-Unis d'Amérique découle du phénomène politique du Trumpisme, lequel est ancré au concept nativisme développé par John Higham. Un américainisme de double axe a été déformé dans une mutuelle et destructive interaction. D'une part, l'américainisme vertical établit un ordre hiérarchisé qui assure le pouvoir d'une classe blanche dominante dans une société qui est homogène en ce qui concerne l'aspect racial et culturel. D'autre part, l'américainisme horizontal, fondé dans les idéaux de Martin Luther King Jr. et Barack Obama, vise à atteindre l'égalité entre les populations, les croyances et les classes sociales diverses. La ligne de couleur (d'après Dubois) est dans une limite dont la tangible tension sépare ces deux axes en déformant culturellement le pays.

Mots-clés: Trumpisme, nativisme, immigration. 


\title{
Introducción
}

\author{
Esta tierra es tu tierra. Esta tierra es mi tierra \\ Desde California hasta la isla de Nueva York; \\ Desde el parque Redwood hasta las aguas de la Corriente del Golfo \\ Esta tierra fue forjada para ti y para mi. ${ }^{4}$
}

Tras completar un viaje desde California hasta Nueva York, en 1940, el trovador y cantautor estadounidense Woody Guthrie compuso «This Land is Your Land». Testigo de las catastróficas consecuencias de la sequía de los años treinta, Guthrie denunció las duras circunstancias económicas de sus compatriotas mientras imaginaba una idílica nación con justicia social para todos. En contraste con la generalizada desigualdad y discriminación de las que fue testigo, Guthrie le cantó a una tierra sin jerarquías sociales ni divisiones; el verso «desde California a la isla de Nueva York» presentaba una horizontalidad de máxima amplitud que imaginaba un país justo. La imagen paradisíaca era la de un lugar donde el Sueño Americano podía ser asequible a todos sin importar su raza, color, credo religioso o género. Entre el sueño y la realidad, siempre hay, no obstante, una gran distancia. En la divisiva época de Trump, con su intolerancia, fanatismo y racismo, prevalece el restrictivo eje vertical que construye murallas, exacerbando el abismo entre la canción de Guthrie y la realidad actual. La pregunta que surge frente a esto es ¿Cuál de ellos representa el verdadero americanismo?

Todo «ismo» requiere de una figura que lo encarne, que defina sus prácticas y lo establezca como un movimiento social reconocible. El presidente de los Estados Unidos de América (EUA) personifica el concepto de América/Estados Unidos y encarna su esencia, como símbolo que modela un período histórico. Desde el momento en que las consignas de «Engrandecer a América» (MAGA) $)^{5}$ y «América Primero» sustituyeron la de «Sí, Podemos» de Barack Obama, la cultura estadounidense ha sustituido la tendencia hacia la integración armónica por otra que promueve las jerarquías exclusivas. La retórica de Trump, marcada por la dicotomía «nosotros» versus «ellos», ha normalizado los ataques racistas al erigir murallas para contener y restringir a la nación horizontal, mientras fortalece el eje ideológico vertical. Frases como «este es mi barrio», «esta es mi ciudad», «este es mi país» o «regrésate a África, México, China» se han vuelto comunes. La presidencia de Trump ha puesto en evidencia que «esta tierra es mi tierra, pero no la tuya». Un hombre portando una cruz esvástica Nazi en Ulysses, Pennsylvania, le declaraba a un reportero de CNN que «las zonas rurales hablaron con fuerza cuando eligieron a Trump», enfatizando en que

\footnotetext{
${ }^{4}$ Guthrie, Woody, Aden G. Lewis, and Jack E. Platt. 1961. This land is your land. New York: Ludlow Music, Inc.

${ }^{5}$ MAGA es la forma abreviada de la consigna «Make America Great Again» que se usará a lo largo del artículo.
} 
«este es mi país» ${ }^{6}$. Esta frase revela que la nación le pertenece de forma exclusiva a un «nosotros» cuyos valores están sincronizados con la ideología de un hombre cuya formidable performance ha convertido a la sociedad estadounidense y al mundo en espectadores de su propio Reality show. Trump se presenta como protector de una nación amenazada por la infiltración de inmigrantes y musulmanes ${ }^{7}$, en un auto engrandecimiento representativo de una cultura cuya verticalidad crea un entorno descoyuntado. El Trumpismo es absurdamente simplista respecto de la raza y cultura: los inmigrantes y la gente de color merecen la desconfianza, la sospecha y la discriminación. La clara atracción ideológica que esto produce en grupos reaccionarios resulta evidente. El talento mediático de showman le permite a Trump desarrollar una forma de tribalismo que crea murallas, dividiendo la nación. Ha sido imposible distinguir entre la agenda oficial de la seguridad nacional, los valores reaccionarios de la extrema derecha y el racismo de los nacionalistas. Camuflados con el atuendo del patriotismo, los que insisten en poner «América Primero» fomentan el descoyuntamiento racial y cultural.

A través de la historia de los EUA, los factores de la raza, el estatus económico, la religión y la sexualidad han ido determinando, en las prácticas los inalienables, derechos de la libertad y búsqueda de la felicidad establecidos en la Constitución. La nación fue concebida sobre la base de estos derechos inalienables y, aunque esto ha contribuido a desarrollar una nación horizontal, hay intereses raciales, religiosos y de género cuyos valores opuestos han establecido una estructura vertical implementada por los grupos dominantes. En múltiples momentos históricos, el statu quo de esta estructura ha sido cuestionado por quienes creen en una nación horizontal. Desde los comienzos de la historia de los EUA, las paradojas y tensiones entre ambos ejes han determinado una intrínseca dualidad conflictiva, expresada a través de negociaciones pacíficas y confrontaciones armadas. Como consecuencia de esta tensión, el americanismo nunca ha devenido un canon rígido y fosilizado, sino una categoría dinámica cuya energía se regenera constantemente de manera transformativa. Esta dinámica, ha creado una nación poderosa y socialmente fluida que ha atraído a quienes buscan el Sueño Americano. Las murallas ideológicas del Trumpismo y una perspectiva aislacionista frenan este proceso y perturban la simbiosis del americanismo, desfigurándolo. Para entender este americanismo de doble eje, se considerará en igual medida la visión idealista, horizontal de Guthrie, así como su contraparte vertical. Al desvincularlas se arriesga a distorsionar la esencia misma de este concepto. Este ensayo delinea una imagen del americanismo desfigurado como producto de la ideología comunicada por «MAGA»y «América Primero».

\footnotetext{
6 Erin Burnett out front, «Swastika-wearing man: this is my country», acceso: 28 de abril de 2021, https://www.cnn.com/videos/us/2018/08/10/ulysses-pennsylvania-sidner-erin-pkg-vpx.cnn

${ }^{7}$ Mimi Yang, «Crossing between the Great Wall of China and the "Great" Wall of Trump», Palgrave Communications 25 (2017): 4.
} 


\section{La ascendencia de la América vertical y el forjamiento del Trumpismo}

El Trumpismo ha profundizado el abismo entre la nación vertical y la horizontal, congregando a los anti-inmigracionistas, anti-musulmanes, antisemitas y anti-LGBTQ, entre otros, bajo la consigna «América Primero». Existe una falsa percepción de que los intereses nacionales se pueden delinear uniformemente en la forma de una muralla, cuya concreta manifestación en la frontera México-Estados Unidos, tiene un alcance cultural mucho más extenso. Las consignas han demarcado la oposición entre quienes erigen las murallas y quienes las atraviesan. En el panorama cultural estadounidense, esta muralla es una línea divisoria entre la base de Trump, autoglorificada como patriotas, en oposición a todos aquellos considerados «no totalmente estadounidenses» o «foráneos». Esta perspectiva cultural se arroga el poder de decidir quiénes se quedan dentro de los confines de la muralla y quiénes no, decidiendo cómo asignar la posesión respecto de la tierra americana en la canción de Guthrie.

«Esta tierra es tu tierra, esta tierra es mi tierra». ¿A quiénes se refieren los posesivos «tu» $\mathrm{y}$ «mi»? ¿Quiénes son los dueños de la tierra estadounidense? Estas preguntas evocan un sinnúmero de historias de usurpación y represión ligadas a intereses económicos, poder sociopolítico, estatus de clase, género, religión y raza. En un país que depende profundamente de la energía nueva traída por olas de inmigrantes, la posesión de la tierra y del ideal que ella simboliza - libertad y democracia - ha sido adjudicada a los vencedores, es decir, gente de antepasados europeos (anglos) con una historia más antigua de inmigración. El hecho de que los indígenas americanos son los ocupantes originales del territorio no ha impedido que, en su condición de vencidos, ocupen los espacios subalternos en la jerarquía social. El temprano asentamiento colonizador de los inmigrantes blancos, anglosajones, protestantes (White Anglo Saxon Protestants o WASPS) aseguró su dominio y poder.

Se sabe que cualquier grupo, sea cual sea su origen, busca establecer medidas para conservar los territorios conquistados. Dado que, desde sus comienzos, el americanismo fue definido por las características de los WASPS, los indígenas, esclavos africanos, trabajadores asiáticos, hispanos, entre otros, tuvieron que adaptarse al concepto de americanismo, firmemente establecido por los WASPs. El no adaptarse, resulta en su categorización, como menos estadounidenses, incapaces de asimilarse en el mejor de los casos y, en el peor, como amenazas a la nación. De forma paradójica, fue precisamente el grupo de WASPs el que trajo consigo los ideales de igualdad, libertad y democracia cuando, tras llegar con mínimas posesiones, aspiraron a realizar su visión de una tierra donde pudieran vivir sin persecuciones. Marginados por la Iglesia anglicana, se enfrentaron a barreras sociopolíticas en el sistema eclesiástico inglés. Cuando Carlos I disolvió el Parlamento británico en 1629, 
los puritanos, acertadamente, lo interpretaron como un acto de hostilidad, lo que determinó su decisión de establecerse en las Américas para construir comunidades basadas en sus creencias. Como otros inmigrantes, se arriesgaron a cruzar el Atlántico, escapando de penosas y difíciles circunstancias. Su esperanza era crear una sociedad justa y libre, desarrollando el modelo de la «Ciudad en la montaña», proclamado por John Winthrop en 1630, cuando le predicó su sermón «Una Ciudad Modelo de Caridad Cristiana» a los primeros colonos en la bahía de Massachusetts ${ }^{8}$. ¿Qué valores podrían ser más democráticos y horizontales que estos? La ironía, sin embargo, es que, a pesar de la naturaleza igualitaria de estas aspiraciones, evitaron cuidadosamente compartirlas con otros inmigrantes, los indígenas, y los africano-americanos, cuyo trabajo creó la infraestructura económica colonial.

Tras casi ocho décadas desde la creación de la canción de Guthrie, esta se asocia con las más progresivas expresiones ideológicas estadounidenses, tales como el Movimiento por los Derechos Civiles de los años 60. La melodía simboliza el espíritu horizontal que aspira a la libertad y la igualdad, configurando un espacio esperanzador para millones de individuos marginados. El americanismo como concepto incluye tanto la nación horizontal como la vertical; pues ambas existen simultáneamente en forma separada, unida e interconectada. Como una dualidad, la desarticulación y el entrelazamiento entre ellas desafía cualquier definición rígida e inalterable, siendo un concepto dinámicamente vital.

La presidencia de Trump, con su aguda intolerancia cultural y acentuado racismo, hace cada vez más urgente dilucidar lo que la nación representa y lo que significa ser estadounidense. La canción de Guthrie, indefectiblemente, sirve como fuente de esperanza en medio de un exacerbado racismo. En aguda contraposición, y basándose en el argumento de los intereses de la seguridad nacional, la política de Trump de separar a los niños de sus familias en la frontera México-EUA, así como su proscripción musulmana, para mencionar solo algunas de sus prácticas, han reforzado una profunda intolerancia y repudio. Aunque ubicado físicamente entre México y los EUA, el muro es una rígida barrera entre razas, religiones y culturas que descoyunta a la nación. Para examinar el desfiguramiento genético del americanismo bajo Trump hay que enfocarse en este muro cultural.

Generaciones de académicos han basado sus estudios en Strangers in the Land: Patterns of American Nativism, 1860-1925, del historiador John Higham (1920-2003), considerándolo como el fundador del nativismo y una autoridad en el tema del americanismo. T. Meagher en «Revisiting John

\footnotetext{
${ }^{8}$ «La ciudad en la montaña» proviene de las escrituras de Mateo 5:14, «Eres la luz del mundo. Una ciudad situada en una montaña no puede esconderse». La frase fue parafraseada por el Puritano John Winthrop en su sermón de 1630 «Un Modelo de Ciudad Cristiana» al primer grupo de colonos en la bahía de Massachusetts. Hoy es parte del léxico político del inglés estadounidense.
} 
Higham's Strangers in the Land: Comment» lo describe así: «Fue parte de uno de los grupos más escasos o menos conocidos del siglo XX, los blancos anglosajones protestantes (WASP) de Nueva York. Creció como un americano privilegiado que, sin embargo, fue considerado fuereño en una ciudad donde casi todos los demás formaban parte de minorías raciales, étnicas o religiosas» ${ }^{9}$. Higham creció dentro del grupo WASP de Nueva York, lo que definía su estatus privilegiado, mientras que los antecedentes diversos de sus contemporáneos les conferían un estatus distinto. Los comentarios de Meagher revelan un innato paradigma cultural, producto del nativismo que el mismo Higham desarrolló: el americanismo es un pilar cultural e ideológico que define de modo exclusivo a quienes pertenecen al grupo blanco y cristiano. Aunque los demás se encuentran presentes en el mismo contexto, no forman parte esencial de la narrativa estadounidense. Simon Van Oort, en su artículo "'Strangers' Revisited: Reading Donald Trump through John Higham» examina las raíces del lema «América Primero»: «Presagiando la política exterior del actual Presidente de Estados Unidos, la Asociación Nacional de Manufactureros confesaba en 1920 que la inmigración ponía en peligro a la nación y proclamaba que las políticas debían apoyarse en la idea básica de poner 'las necesidades e intereses de América primero' ${ }^{10}$.

La obra de Higham explora la identidad cultural estadounidense alrededor de la década de 1860, cuando la llegada en masa de inmigrantes, especialmente de origen católico-irlandés, entre 1860 y 1925 incitó a considerar su impacto respecto a la identidad nacional. Las facciones anti-extranjeros que surgieron en Nueva York y otros lugares después de 1835, se transformaron durante la década de los 1850 en los disturbios civiles llamados Know-Nothing. Estas facciones se agrupaban bajo el nombre de nativo americanos o simplemente el partido americano ${ }^{11}$. Cuando esta filosofía nativista fue identificada como americanismo, cualquier posibilidad de definir de otra forma los principios culturales de la nación desapareció. Higham declaraba que el gran logro del partido americano es «el principio de nacionalidad», tal como fuera proclamado en una de las publicaciones del Know-Nothing en 1855. Allí se afirmaba que, respecto del americanismo, «debemos hacer algo para protegerlo y vindicarlo. Si no lo hacemos, será destruido» ${ }^{12}$. Trasladándonos al Trumpismo del siglo XXI, el mismo texto diría: nos enfrentamos a una amenaza contra nuestra nación por parte de la gente de color, de religiones, valores y lenguas distintos de los nuestros. Profundamente influenciados por el nativismo de Higham, quienes apoyan a Trump lo perciben como protector del pais, guardián de sus valores e intereses.

\footnotetext{
${ }^{9}$ Timothy Meagher, «Revisiting John Higham's 'Strangers in the Land': Comment», Journal Gilded Age Progress Era 11, n. ${ }^{\circ}$ (2012): 282.

${ }^{10}$ Simon Van Oort, «Strangers Revisited: Reading Donald Trump through John Higham», acceso: 28 de abril de 2021, http://www.baas.ac.uk/usso/strangers-revisited-reading-donald-trump-through-johnhigham/\# ftnl

${ }_{11}$ John Higham, Strangers in the land: patterns of American nativism 1860-1925 (New Brunswick: Rutgers University Press [1954] 2002), 4.

${ }^{12}$ La fuente de esta cita es el diario de los Know-Nothing incluido en Higham, 4. 
De acuerdo con el nativismo, la nación vertical existe para sostener una jerarquía cultural que codifica, de modo exclusivo, lo que significa ser estadounidense, sirviendo perfectamente para el desarrollo de las consignas de Trump, quien supo manipular el temor de la clase media, típicamente compuesta de blancos relegados por la imperante globalización. Sus consignas encontraron un eco favorable entre los conservadores, la facción alt-right_y los nacionalistas blancos listos a expulsar a los «forasteros». En una época en la que la narrativa vertical requería una ideología fundacional, el nativismo sirvió para conferirles «honra» a los WASPS, asegurándoles una «honorable» dominación a fines del siglo XIX y comienzos del XX. Higham abordó el dominio cultural como una cuestión existencial indicando: «¿Consiste el nativismo solo en un específico conjunto de actitudes dominantes en la cruzada anti-extranjera de mitades del siglo XIX? ¿O se extiende a cada instancia en que los habitantes de un país se enfrentan contra los extranjeros?» La identificación de los WASPs como los nativos de la nación, establecía inequívocamente la ideología nativista de la verticalidad que conecta el nativismo y el nacionalismo blanco, haciéndolos intercambiables. Leonard Dinnerstein y D. M. Reimers han indicado que Higham originalmente había planeado escribir sobre el nacionalismo americano, pero la tarea lo sobrecogió, pues «al examinar sus materiales en detalle comenzó a darse cuenta de que el nacionalismo americano tendía a establecer la distinción entre grupos privilegiados y grupos excluidos. El grupo privilegiado estaba formado por la raza dominante blanca protestante, que se opuso a la masiva inmigración europea en los años posteriores a $1880 \gg^{13}$.

La homogeneidad religiosa, lingüística, racial e ideológica del grupo privilegiado facilitó su vinculación al nativismo, mientras que, en contraste, la diversidad del grupo excluido impedía adjudicarle una narrativa unificada. Ausentes del nativismo de Higham, estaban los indígenas, habitantes originales del territorio americano, pues convenientemente, los colonos protestantes olvidaron el hecho de que ellos también fueron inmigrantes y que eran y son precisamente los indígenas los legítimos nativos de los EUA. Esta exclusión discursiva refleja su exterminio literal en el desarrollo del concepto de nacionalismo estadounidense. Este burdo olvido muestra la estrecha conexión entre etnocentrismo, culturocentrismo y teocentrismo; solamente los WASPs son considerados como los verdaderos estadounidenses y dirigentes de facto de la nación. Los inmigrantes irlandeses, mexicanos y chinos, entre otros, son para Higham, «extraños»y, por ende, «noestadounidenses», es decir, una amenaza a «nuestros» valores, pues supuestamente les quitan oportunidades a los legítimos estadounidenses. Lo extraordinario es que en este siglo XXI se es testigo de una mentalidad similar en la nación de Trump, ya que los «nativistas» actuales y los descritos por Higham perciben la realidad de modo similar. La hegemonía y etnocentrismo

${ }^{13}$ Leonard Dinnerstein y David M. Reimers, «John Higham and Immigration History», Journal of American Ethnic History 24, n. ${ }^{\circ} 1$ (2004): 6. 
de los WASPS de mediados del siglo XIX produjo conmoción y resentimiento culturales, religiosos y raciales. Quienes se habían autoproclamado dueños de los recursos y la cultura temían que los irlandeses los despojarían de sus privilegios y oportunidades, tal y como hoy los miembros de la clase media blanca temen que los mexicanos y otros inmigrantes usurparán los suyos. Este paralelo se extiende a la intolerancia previa hacia los católicos con la actual respecto de los musulmanes. La polarización de Higham entre estadounidenses versus no-estadounidenses, basada en orígenes nacionales aún define la actual disposición anti-inmigratoria. En su homogeneidad, los nativistas contemporáneos se auto perciben como estadounidenses, reviviendo lo que Higham describía como «una intensa oposición a las minorías domésticas con base en sus conexiones extranjeras»» ${ }^{14}$.

Para eliminar los enemigos internos y las minorías, la orden presidencial de enero del 2017 «Seguridad Fronteriza y Mejoramiento de la Ejecución Inmigratoria» puso en marcha la construcción de una muralla en la frontera EUA-México. Otra orden ejecutiva implementó una «Proscripción Musulmana» de facto dándole instrucciones al Departamento de Seguridad de la Nación y el Departamento de Estado para reducir el número de inmigrantes musulmanes y rechazar la entrada de refugiados de seis países musulmanes. Exacerbando el odio y la intolerancia de su base política, el presidente catalogó a los mexicanos como criminales y violadores mientras compartía con su audiencia la opinión de que los inmigrantes de África y Haití provenían de «países de mierda». A esto hay que añadir sus esfuerzos por revocar el estatus de $\mathrm{DACA}^{15}$ destruyendo las esperanzas de jóvenes inmigrantes. De forma fraudulenta la consigna de "América Primero» desfigura el americanismo precisamente cuando el flujo migratorio se ha vuelto una parte integral de los mercados, comunidades y redes globalizadas. Los que insisten en el patriotismo de «América Primero» ignoran cómo esto ha resultado en una discriminación exacerbada contra los inmigrantes legales. La compañía Macy's, por ejemplo, ha discriminado contra sus empleados al exigir pruebas adicionales de estatus migratorio para conservar su trabajo, usando el pretexto de la seguridad nacional y dicha consigna. Esta discriminación laboral basada en ciudadanías de origen es copia fiel de lo ocurrido durante el auge del nativismo contra los inmigrantes irlandeses. La consigna trae adicionales connotaciones para grupos religiosos diversos, especialmente para los musulmanes americanos. Si la palabra «América» es monopolizada por la nación vertical ¿Significa que los musulmanes deben ser considerados como no-estadounidenses en el mejor de los casos y terroristas en el peor? Quizás el acto más tristemente célebre de Trump para deshacerse de la minoría interna sobre la base de sus conexiones extranjeras, base de la consigna de "América Primero», es el premeditado «movimiento de nacimiento» ${ }^{16}$ contra el expresidente Obama. El núcleo de la América vertical

\footnotetext{
${ }^{14}$ Higham, Strangers..., 4.

${ }^{15}$ Deferred Action for Childhood Arrivals (DACA).

${ }^{16}$ Mi traducción del término «birther movement».
} 
no pudo ni puede aceptar el hecho de que un hombre negro ocupara el puesto más poderoso del mundo como comandante en jefe de los Estados Unidos. Su incapacidad de cruzar la línea del color, según el término acuñado en 1903 por W.E.B. Du Bois en Souls of Black Folk, motivó su sentido de amenaza frente al ascenso político de Obama. Para apaciguar sus temores existenciales, este grupo se vio en la necesidad de deslegitimizar a Obama al intentar probar que no había nacido en los EUA y que no tenía derecho de ser presidente. Para la nación horizontal, en contraste, la elección de un presidente negro constituyó un momento histórico crucial. Su triunfo significó la victoria de los marginados al darles esperanza a los afro-americanos y otras minorías de influenciar el núcleo de las instituciones regidas por los grupos dominantes. La incompatibilidad de las dos perspectivas culturales - la dominación blanca y el triunfo de los marginados - desencadenó un racismo organizado en contra de la persona cuya función era proteger precisamente las instituciones y ciudadanos que trataban de destruirlo. Un americanismo desfigurado lo colocó en la insostenible posición de proteger los derechos de los nativistas, cuyo objetivo era rechazarlo por su raza.

\section{Mapeo de la América horizontal y la configuración del americanismo}

El ser una nación de inmigrantes con enorme diversidad racial y étnica plantea preguntas ineludibles: ¿A quién le pertenece la cultura estadounidense? ¿Cómo esbozar los contornos y colores de su identidad cultural? Para intentar responder se llega invariablemente al choque de ideologías agrupadas en los ejes vertical y horizontal. La nación vertical exige límites precisos para mantener la hegemonía del statu quo; la horizontal es un producto de facto de la anterior sin otra alternativa que la de mantener un borde fluido que incorpora a todo(s) lo(s) los excluidos por aquélla. Su fluidez moldeable le permite extenderse al eje vertical cuando surge la oportunidad. Ambas, sin embargo, utilizan el filtro racial para establecer la división que las ha configurado «genéticamente». Para examinar la nación horizontal enfrentada al Trumpismo, un marco de análisis cultural basado en la raza es imprescindible.

En toda sociedad existen jerarquías que luchan para obtener control y privilegios. Entre los elementos sociales definitorios es posible que la raza sea el más divisivo, pues a diferencia de otros, es la más reconocible durante el diario interactuar. Las percepciones son fácilmente determinadas por los estereotipos, prejuicios y, lo más obvio, el color de la piel. La falta de empatía y conocimiento facilitan una comunicación y percepción superficial. La diferencia racial promueve el distanciamiento y guía falsamente la jerarquización de culturas y modos de pensar, ya que encasilla con mayor rigor que la religión, género, ideología política o clase social. En el contexto estadounidense, la línea del color es un frente convergente y divergente. Tras 
la llegada del barco Mayflower, en el siglo XVII, los puritanos ingleses entraron en contacto con los indígenas; con el comercio de esclavos africanos en los siglos XVII y XVIII, las razas blanca, indígena y negra entraron en contacto, pero no se mezclaron. El resto es la larga historia multirracial de la inmigración estadounidense. En un país multirracial y multicultural, la raza determina las identidades individuales y colectivas, moldea las conciencias, construye relaciones de poder, determina el entendimiento de igualdad e inclusión, transforma instituciones y crea olas culturales. En su reseña del libro America Beyond Black and White de Ronald Fernández (2007), Víctor M. Rodríguez indica categóricamente: "Aunque América es una nación de inmigrantes, los inmigrantes han sido divididos y categorizados de acuerdo a su raza, loados y despreciados», añadiendo que el «trayecto histórico y racial de los EUA en el cual Fernández lleva a sus lectores nos recuerda la relación entre inmigración, cultura y raza $\gg{ }^{17}$. En medio de una multitud de colores y formas, la raza, la cultura y la inmigración actúan como principales movilizadores.

Sin una definición explícitamente unificadora de americanismo, el concepto de «ceguera al color» ha dado fuerza a los marginados, carentes de poder político, buscando borrar la línea del color y sus concomitantes económicos y sociopolíticos. Esto unifica la nación horizontal y reduce «la racialización y el pensamiento racialista» ${ }^{18}$. Quienes participan de este esfuerzo van cambiando según el panorama sociopolítico; sin embargo, cada oleada de participantes contribuye nuevos elementos al proceso. Al enfrentarse a los lemas culturalmente codificados de «América Primero» y «MAGA»la ceguera al color es fundamental para entender la América horizontal como la definición auténtica del americanismo. Para examinar lo anterior, se debe resaltar dos figuras icónicas: Martin Luther King Jr. y Barack Obama.

El Dr. Martin Luther King Jr. reconoció la existencia de las dos naciones en su discurso del 14 de abril de 1967 «La Otra América» ${ }^{19}$ en la Universidad de Stanford. Como parte del evento «Saludo a la Libertad» organizado por el sindicato Local 1199 de Nueva York, el Dr. King primeramente caracterizó a la nación privilegiada y próspera: «Hay literalmente dos Américas. En una fluye la leche de la prosperidad y la miel de la igualdad. Esa América es el hábitat de millones de personas que tienen comida y satisfacen las necesidades materiales de sus cuerpos, cultura y educación para sus mentes, libertad y dignidad para sus almas». Sin mencionar la sociedad blanca, la mención de prosperidad, comida, cultura, educación, dignidad y oportunidad se refiere directamente a ella. Al referirse a la nación marginada, coexistiendo

\footnotetext{
${ }^{17}$ Víctor M. Rodríguez, «America Beyond Black and White: How Immigrants and Fusions are Helping US Overcome the Racial Divide», Centro Journal 21, n. ${ }^{\circ} 1$ (2009): 264.

${ }^{18}$ Víctor M. Rodríguez, «America Beyond...», 265.

${ }^{19}$ A lo largo de este artículo todas las citas del discurso «The Other America» fueron transcritas del video en https://www.youtube.com/watch? $\mathrm{v}=\mathrm{m} 3 \mathrm{H} 978 \mathrm{KlR} 20$ y comparadas con párrafos del libro The Radical King, publicado por Beacon Press, 2015, http://www.beacon.org/The-Radical-KingP1049.aspx. Las transcripciones son de la autora.
} 
con los privilegiados, el Dr. King reconoció estar dolorosamente consciente del hecho

de que hay otra América y que esta contiene una cotidiana fealdad que transforma el optimismo de la esperanza en la fatiga del desespero [...] En esta otra América, miles, si, millones de jóvenes se ven forzados a asistir a escuelas inadecuadas, inferiores, de ínfima calidad, no porque son tontos, no porque carecen de inteligencia innata, sino porque las escuelas son tan deficientes, abarrotadas, carentes de calidad y segregadas, que los mejores contenidos de sus mentes jamás serán expresados.

Sin mencionar una raza específica, el Dr. King describe las duras condiciones de vida de los desposeídos, enfocándose en un sistema educacional segregado como el factor determinante de esta realidad; la línea del color que moldea las jóvenes mentes negras, blancas y marrones. Richard Merelman indica:

En los Estados Unidos, el aislamiento racial supera aquél basado en los factores de género, clase, o etnia blanca. Las leyes federales ni siquiera requerían que negros y blancos tuvieran acceso a las mismas escuelas públicas sino hasta 1954; en contraste, nunca se segregó a hombres y mujeres ricos y pobres, polacos y WASPs en dichas escuelas $^{20}$.

A medida que los niños participan de este sistema segregado, surgen sus prejuicios raciales, sentido de separación y etnocentrismo cultural. El Dr. King continúa indicando que la segregación racial creó dos tipos de discurso para describir condiciones económicas y estatus social similares:

La realidad es que el hombre negro en los Estados Unidos de América se enfrenta a una depresión literal. Pero ustedes entienden que no se la llama así. Al desempleo masivo en la comunidad negra, se lo llama un problema social. En contraste, el desempleo masivo en la comunidad blanca se lo llama depresión. Para el hombre negro hay «prestaciones sociales», pero para los blancos hay «subsidios». En este país el socialismo es para los ricos, y el robusto individualismo para los pobres ${ }^{21}$.

Frente al hecho de que las dos Américas hablan diferentes idiomas, cabe preguntarse: ¿Se abandonará para siempre a los desposeídos por esta incomunicación? El Dr. King trató de ser el «traductor» entre ellas, al entender que, como tal, el traductor debe dominar ambas lenguas, comprender

\footnotetext{
${ }^{20}$ Richard Merelman, «Racial conflict and cultural politics in the United States», Journal of Politics 56, n. ${ }^{\circ} 1$ (1994): 5.

${ }^{21}$ Calin Gilea, Dr. Martin Luther King Jr. at Stanford, «The other America», 1967, acceso: 18 de marzo del 2018, video $47 \mathrm{~m} 54$ s, https://www.youtube.com/watch?v=3H978K1R20
} 
ambas Américas. En su momento, sin embargo, la raza dividía a los estadounidenses en estatus económicos y sociales con total asimetría de poder; por ello, comprendió que distinguir específicamente a los afroamericanos de entre los marginados, los convertiría en blanco de ataques. Al abordar las desigualdades de varios grupos marginados, consiguió ampliar sus bases de apoyo y las posibilidades de convertir su sueño en realidad. Como el traductor de ambas Américas, intentó evitar el pisar la divisoria línea de la raza usando en su lugar el idioma universal de los intereses económicos, el sustento, trabajos y oportunidades para construir un frente unido en su lucha por la igualdad y la justicia.

La raza es el factor que divide ambos ejes de la nación. Mientras que cada uno retiene su propio ideal de americanismo y del Sueño Americano, ni uno ni el otro puede superar la línea del color. Sin importar cuánto, el Dr. King deseaba incluir en su base a diversos grupos raciales y étnicos, nunca dejó de mencionar la división entre blancos y negros. El desafío de sanar las cicatrices raciales dejadas por las profundas heridas históricas se combina con el de separar el estatus económico y las clases sociales del ámbito racial. En la tarea de unificar a la nación la experiencia afroamericana es un punto obligado de referencia respecto de la discriminación y rechazo por parte de la América vertical. Otros grupos poblacionales se identifican con la lucha de los afroamericanos al compartir el Sueño Americano desde los márgenes, el mismo imaginado por el Dr. King en su discurso «Tengo un Sueño» («I Have a Dream»). Apoyado en la experiencia afroamericana, pero sin confinarse a ella, el Dr. King convocó a una coalición con los matices del arcoíris cuando creó el movimiento multirracial «La Campaña de la Gente Pobre» en 1963 y emplazó a sus integrantes a resucitar sus esperanzas en su discurso «Tengo un Sueño». En su lucha por lograr salarios comparables, igualdad de oportunidades y, de modo aún más básico, la posibilidad de no ser juzgado por el color de la piel, su deseo se convirtió en sinónimo del Sueño Americano y del americanismo horizontal. El Dr. King soñó que «un día esta nación se levantará para vivir el verdadero significado de su creencia: sostenemos que estas verdades son evidentes en sí mismas, que todos los hombres son creados iguales» $^{22}$. Su «ceguera del color» fue construida sobre intereses y luchas compartidas, permitiéndole transcender el dolor y angustia afroamericanos y apelar a una amplia gama de americanos económicamente desposeídos.

Las tensiones raciales, culturales y las divisiones religiosas del siglo XXI ¿Son diferentes de las que existían en la década de los 60? Aunque estos problemas son tangibles en la actual vida sociopolítica de la nación, una antítesis ha surgido en la arena política racial y cultural: Donald Trump y Barack Obama.

\footnotetext{
${ }^{22}$ Martin L. King, «I Have a Dream», Speech presented at the March on Washington for Jobs and Freedom, Washington, D.C., August 1968, https://avalon.law.yale.edu/20th century/mlk01.asp
} 
En el presente, ambas Américas se han polarizado al revivir las tendencias jerárquicas, el nativismo exclusivo encarnado en los nacionalistas blancos, la alt-right, los neo-Nazis y el KKK. El Trumpismo e individuos como Steve Bannon han renovado el nativismo de Higham, para privilegiar exclusivamente a la raza blanca. En contraste con lo anterior, la elección presidencial de Obama en el 2008 fue un hito crucial que superó la línea del color, en cumplimiento del sueño de King. Las estadísticas revelaron que el triunfo de Obama resultó de la combinación del apoyo de afroamericanos, asiático-americanos, hispanos e indígenas americanos, incluyendo el voto blanco. Su triunfo resultó de la porosidad entre ambas Américas, implicando que la línea del color no es rígida. La suya fue una jornada cuesta arriba para ascender a la cumbre del núcleo del poder. Si el americanismo horizontal de Martin Luther King se sostuvo en su «ceguera del color» y su dominio de un lenguaje interracial para dirigirse a los desposeídos ¿Cómo se sostiene el americanismo de Obama? A la respuesta se llega a través de tres puertas interconectadas: el patriotismo, la esperanza y la «ceguera del color». Esto hace comprensible su antítesis básica respecto de Trump.

El patriotismo de Obama es el núcleo de su americanismo. Desde muy temprano reconoció la existencia de la línea del color que lo excluía, etiquetándolo como un extraño. Dado que para la nación vertical el color de su piel y su nombre, Barack, son percibidos como «no-estadounidenses», la única opción era ubicarse en el eje horizontal desde el cual adquirió conciencia del esfuerzo adicional necesario para lograr el éxito. Aunque su padre keniano no fue una presencia central durante su niñez, el Sueño Americano y su visión de EUA como un faro de libertad influyeron en su hijo. Criado principalmente por su madre y abuelos maternos de raza blanca, el joven Barack aprendió de ellos el Sueño Americano de la clase media. El sueño paterno, el cosmopolitismo de su madre y el Sueño Americano de sus abuelos moldearon los valores del futuro presidente, desarrollando un americanismo sostenido por diversas perspectivas culturales integradas entre sí.

La multiplicidad cultural y racial de Obama ha desajustado a los nacionalistas blancos y nativistas partidarios de Trump. Desde su visión de mundo, los antecedentes familiares multiculturales, el color de piel y nombre raro ${ }^{23}$ convirtieron a Obama en un extraño sin derecho a demandar la ciudadanía estadounidense, al extremo de poner en entredicho su lugar de nacimiento. Cabe preguntarse, si su padre keniano hubiera sido un europeo blanco protestante ¿Se habría verificado este dato? El Trumpismo ha confinado la categoría de estadounidense a la membresía del club de los nacionalistas/nativistas blancos. En contraste, el patriotismo de Obama sostenido por la pluralidad de perspectivas raciales y culturales ha expandido el horizonte del americanismo del siglo XXI. Ello fue expresado claramente

${ }^{23}$ Barack Obama, Audacity of Hope: thoughts on reclaiming the American Dream (New York: Crown Publishers, 2006), 362. 
en su discurso, «Out of Many, One» («De muchos, uno») de 2004, en el que afirmó:

Hablo de algo más fundamental. Hablo de la esperanza de los esclavos sentados alrededor del fuego entonando canciones de libertad, la esperanza de los inmigrantes dirigidos a costas lejanas, la esperanza de un joven teniente naval valientemente patrullando el delta del Mekong, [...] la esperanza de un chiquillo flaco con un nombre raro que está convencido de que hay cabida en América para él también ${ }^{24}$.

Al ubicar su narrativa dentro del linaje histórico-cultural de EUA, Obama conectaba su historia a ambas Américas en un rol similar al Dr. King como traductor cultural entre ellas. D. Atwater señala que «la retórica de la esperanza [es] el uso de símbolos para invitar a los americanos a preocuparse por el país, a creer recuperando la fe y la esperanza en él, y entender que tenemos más similitudes que diferencias compartiendo un destino y un conjunto de valores» ${ }^{25}$.

El deseo de Obama de recuperar el Sueño Americano se sostiene en la «ceguera del color», postulando que no hay una nación blanca, otra negra, otra latina, otra asiática, etc., sino solamente una: Estados Unidos de América. $\mathrm{Su}$ recuperación del Sueño Americano, guiada por la ceguera al color, es importante para todos los estadounidenses, incluso los nacionalistas blancos. En contraste con Trump, que amplía la división racial, creando intolerancia y desconfianza, el americanismo de Obama ofrece una visión «liberada del pasado de Jim Crow y la esclavitud, los campos de internamientos japoneses, los braceros mexicanos, las tensiones laborales y los conflictos culturales una América que cumple la promesa del Dr. King de ser juzgados por el carácter y no el color de nuestra piel» ${ }^{26}$. Obama se ha enfocado en la humanidad compartida de los estadounidenses desde una posición marginada. Si Trump construye murallas para dividir, Obama trató de eliminarlas indicando: "Quizás más que en ningún otro momento de nuestra historia reciente, necesitamos de un nuevo tipo de política, una política que pueda excavar y construir sobre la base de nuestro entendimiento compartido que nos une como americanos» ${ }^{27}$. Obama planteaba su convencimiento de que la política se puede basar en el bien común al captando la esencia de lo que es ser estadounidense y encarnar el Sueño Americano que atrajo a su padre y a millones de personas. Este Sueño Americano «es un paradigma sedimentado desde un origen colectivo y la conciencia de un grupo» ${ }^{28}$, un sueño que «convirtió en realidad una nación y una cultura; [que] creó una tierra de

${ }^{24}$ Barack Obama, «Out of many, one», Washington Post, 24 de julio de 2004, acceso: 28 de abril de 2021, http:/www.washingtonpost.com/wp-dyn/articles/A19751-2004Jul27.html

${ }^{25}$ Deborah Atwater, «Senator Barack Obama; the rhetoric of hope and the American dream», Journal Black Studies 38 n. ${ }^{\circ} 2$ (2007): 123.

${ }^{26}$ Barack Obama, Audacity..., 231.

${ }^{27}$ Barack Obama, Audacity..., 9.

${ }^{28}$ Mimi Yang, The Tricultural..., 104. 
ensueño que atrajo a más soñadores para venir y crear más sueños [...]. Fue el sueño de vivir sin persecuciones el que trajo a un grupo de Puritanos arriesgando sus vidas para arribar a estas costas ${ }^{29}$.

Al enfrentarse a la realidad de dos o múltiples Américas, factores divisivos como la raza, religión, género, tradición, riqueza, clases sociales trazan constantemente líneas de inclusión y exclusión. A múltiples niveles, la exclusión predomina sobre la aceptación, en particular para la comunidad afroamericana, ya que la sociedad no ha cumplido las promesas de justicia y libertad para todos. La eliminación de las divisiones no se ha logrado, aunque se ha intentado minimizar y sanar las heridas. Mientras la nación vertical se enfoque en mantener su dominio cultural y statu quo, la horizontal permanecerá subordinada a la narrativa dominante del americanismo actual y su proyecto de cortar y separar, desfigurando la nación.

\section{Conclusiones}

La interacción constante de la dualidad del americanismo le da porosidad al concepto de América. La dualidad de la América vertical y horizontal no está hecha para que la línea del color las separe y jerarquice, sino para conectarlas a pesar de los obstáculos. El artículo de CNN de Moni Basu Basu, «Vino a este país con \$200 y esperanza. Cómo el sueño americano de Khizr Khan lo llevó a la confrontación con Trump», lo comprueba. Basu señala cómo

El Sr. Khan llegó a Estados Unidos a finales de 1979, trayendo una valija Samsonite de color plateado y \$200 [...] un esforzado inmigrante paquistaní $[. .$.$] realizó su sueño de graduarse de abogado$ de la Escuela de Derecho de Harvard. Con su esposa de 43 años, Ghazala, criaron tres hijos, uno de los cuales fue a Iraq con el rango de capitán y regresó en un ataúd.

Las palabras del abogado Khizr Khan, musulmán americano, fueron impactantes en el 2016. Cuando habló de su hijo Humayun Khan, nacido y criado en EUA, condecorado con el Corazón Púrpura, por su sacrificio, el Sr. Khan enfatizó el sentirse «orgullosos ciudadanos de Estados Unidos», añadiendo que «Son los valores (de este país) lo que nos trajo acá, no nuestra religión. La posición de Trump no representa esos valores». Su comentario directamente referido a la prohibición de facto a la entrada de musulmanes al país, planteaba la urgente pregunta para todos, pero especialmente los adherentes al nativismo ¿Cómo puede un inmigrante de color y musulmán amar este país de igual forma que un cristiano de raza blanca nacido y criado aquí? ¿Cómo la familia Khan puede vivir y morir defendiendo la Constitución, la democracia y libertad? En esta instancia, la dualidad de lo vertical y lo horizontal se entrelazan en una dependencia que supera su mutuo rechazo. El respeto de Khizr Khan por la Constitución y el país, cruza las

\footnotetext{
${ }^{29}$ Mimi Yang, The Tricultural..., 104.
} 
divisiones raciales y religiosas. Entonces ¿Acepta la nación vertical con su autoproclamado patriotismo a este inmigrante musulmán? ¿O lo rechaza como una amenaza? Ningún estadounidense está exento de responder estas preguntas. La ruta seguida por Khan es simbólica y representativa, a pesar y por sobre la actual división sociopolítica endurecida bajo la influencia de Trump, para bien o mal.

En teoría, el americanismo confiere el espacio para llevar a cabo las negociaciones y transformaciones inherentes a la dualidad. Según las palabras de Emma Lazarus, en 1883, grabadas en la Estatua de la Libertad, esta les extiende la mano a los cansados y pobres, dando la bienvenida a los desposeídos. Al revelar cómo los orígenes de la turbulencia actual residen en el nativismo de Higham, vemos que el Trumpismo es una renovada expresión de un americanismo rígido, que paraliza la dualidad cultural distorsionando la promesa de grandeza nacional.

\section{Formato de citación según APA}

Yang, M. (2021). Trumpismo: Un americanismo desfigurado. Revista Espiga, 21 (41), páginas 103-120.

\section{Formato de citación según Chicago-Deusto}

Yang, Mimi. «Trumpismo: Un americanismo desfigurado». Revista Espiga 21, n. ${ }^{\circ} 41$ (enero-junio, 2021): páginas 103-120.

\section{Referencias bibliográficas}

Atwater, Deborah. «Senator Barack Obama; the rhetoric of hope and the American dream». Journal Black Studies 38, n. ${ }^{\circ} 2$ (2007):121-129.

Basu, Moni. «He came to this country with \$200 and hope. How Khizr Khan's American dream led him into a battle with Trump». Acceso: 28 de abril de 2021. https:/edition.cnn.com/2018/07/20/us/khizr-khan-the-making-ofan-activist/index.html

Dinnerstein, Leonard y David M. Reimers. «John Higham and Immigration History». Journal American Ethnic History 24, n. ${ }^{\circ}$ (2004): 3-25. 
Gilea, Calin. Dr. Martin Luther King Jr. at Stanford. «The other America», 1967. Acceso: 18 de marzo del 2018. Video 47 m 54 s. https:/www.youtube.com/watch?v=3H978K1R20

Higham, John. Strangers in the land: patterns of American nativism 1860 1925. New Brunswick, NJ: Rutgers University Press, [1954]/2002.

King, Martin L. «I Have a Dream». Speech presented at the March on Washington for Jobs and Freedom, Washington, D.C., August 1968. https://avalon.law.yale.edu/20th_century/mlk01.asp

Meacham, John. The soul of America: the battle for our better angels. New York: Random House, 2018.

Meagher, Timothy. «Revisiting John Higham's 'Strangers in the Land': Comment'». Journal Gilded Age Progress Era 11, n. ${ }^{\circ} 2$ (2012): 282-290.

Merelman, Richard. «Racial conflict and cultural politics in the United States». The Journal of Politics 56, n. ${ }^{\circ} 1$ (1994): 1-20.

Obama, Barack. Audacity of hope: thoughts on reclaiming the American Dream. New York: Crown Publishers, 2006.

Obama, Barack. «Out of many, one». Washington Post, 27 de julio de 2004. Acceso: 28 de abril de 2021, http://www.washingtonpost.com/wpdyn/articles/A19751-2004Jul27.html

Rodríguez, Víctor M. «America beyond Black and White: how immigrants and fusions are helping US overcome the racial divide». Centro Journal 21, n. ${ }^{\circ} 1$ (2009): 264-268.

Van Oort, Simon. «Strangers Revisited: Reading Donald Trump through John Higham». U.S. Studies Online, 27 de febrero de 2017. Acceso: 28 de abril de 2021. http://www.baas.ac.uk/usso/strangers-revisited-reading-donaldtrump-through-john-higham/\#_ftnl

Winthrop, John. A model of Christian charity. The journal of John Winthrop, 1630-1649. Cambridge: Harvard University Press, 1996.

Yang, Mimi. «Crossing between the Great Wall of China and the 'Great' Wall of Trump». Palgrave Communications 25, (2017): 1-6.

Yang, Mimi. The tricultural personality (Chinese, Hispanic, English): a paradigm for connecting culture differences. New York: Edwin Mellen, 2014. 